\title{
Effect of steaming and frozen storage on polyphenol content and antioxidant properties of Mangifera odorata (Kuini) pulp
}

\author{
*Norra, I., Saiful Bahri, S., Hadijah. H. and Norhartini, A.S. \\ Food Science and Technology Research Centre, Malaysian Agricultural Research and Development \\ Institute, MARDI Headquarters, Persiaran MARDI-UPM, 43400 Serdang, Selangor
}

\begin{abstract}
Article history:
Received: 12 May 2020

Received in revised form: 24

August 2020

Accepted: 27 September 2020

Available Online: 24 January

2021
\end{abstract}

Keywords:

Steaming,

Polyphenol content,

Antioxidant properties,

Mangifera odorata (kuini),

Frozen storage

DOI:

https://doi.org/10.26656/fr.2017.5(1).219

\section{Introduction}

Fruits deliver numerous health benefits to the human body because they are important sources of phytochemicals in the human diet, especially polyphenols that possess high antioxidant capacity. Antioxidants are substances that can prevent or slows damages to cells caused by free radicals, molecules that the body produces as a reaction to environmental and other pressures. Consumption of fruit is one of the best methods to provide protection against cardiovascular disease (CVD), several common types of cancer, and other chronic diseases (Serafini, 2006). Besides antioxidants, it is also rich in vitamins and minerals. Other than that, fruits are an excellent source of soluble dietary fiber that can help in smooth bowel movements.

Generally, more than 370 species of fruits can be found in Malaysia and 16 species are classified as primary fruits, while the rest are new or rare fruits, which also referred to as underutilized fruit species (Norlidawati and Nik Rozana, 2016). Majority of the fruits in the group were new or rare fruits which refer to underutilized group and 16 species of primary fruits. Most of the important underutilized fruits are indigenous.

In Malaysia, Mangifera odorata is one of the common underutilized fruits. M. odorata or locally known as kuini belonged to the family Anacardiaceae. The fruit emits fragrance smell, light orange in color and juicy sweet when ripe. Among 14 Mangifera species that been found in Malaysia, there are four common and widespread species being cultivated in all the 11 states throughout the country. These 4 species are Mangifera indica (mangga), M. odorata (kuini), M. foetida (bacang) and M. caesia (binjai) (Salma et al., 2010). Previous researches on different parts of Mangifera fruits showed that members of this genus have the potential to act as antioxidant. Even though many studies have been focused on antioxidant properties of commercial mango ( $M$. indica), antioxidant properties of $M$. odorata were also been studied by Khoo et al. (2008) Mirfat et al. (2016) and Nur Fatimah et al. (2019). However, to the best of our knowledge none of these studies report the 
effect of thermal processing treatment (steaming) on polyphenol content and antioxidant properties of kuini fruits.

Kuini was not widely grown and rarely found in the market since not cultivated commercially. Due to that fact, fans of these fruits are looking forward to the season that only available once a year. A short ripening season of this fruits lasting only a few weeks requiring their use as processed fruits in the off-season. Other than that, kuini are highly perishable and difficult to store in the fresh form, thus it could easily deteriorate within a few days after harvest. To preserve this perishable fruit, some processing methods can be applied along with enhancement of nutritional properties and sensorial quality. Fruit pulp is the most basic food product obtained from fresh fruit processing. It can be cold stored for long periods and commercially processed into valueadded products such as juices, ice creams, sweets, jellies and etc.

In this study, the production of kuini pulp involving steam blanching technique at different processing time before being frozen at $-18^{\circ} \mathrm{C}$ for further use. Some studies have shown that thermal treatment, including steaming, will decrease antioxidant components and antioxidant activities. However, in contrast, other studies reported that thermal treatment increases the total phenolic content and radical scavenging abilities of vegetables (Kim et al., 2013).

Therefore, the purpose of this study was to investigate the effect of steaming treatment of frozen kuini pulps in the content of total phenolics (TPC) and the antioxidant activity (AOA). This study was also to evaluate the changes of TPC and AOA of frozen kuini pulps during 12 months of storage. Apart from that, the obtained result will be used to determine the optimal steam blanching time for processing kuini pulp.

\section{Materials and methods}

\subsection{Chemical and reagents}

Methanol AR Grade, Hydrochloric acid 6.0 N, Gallic acid, Trolox, 2,2-diphenyl-picrylhidrazine (DPPH) and 2,4,6-Tris (2-picryl)-s-triazine (TPTZ) from Sigma (Germany), sodium carbonate anhydrous and sodium acetate 3-hydrate brand Bendosen, Folin ciocalteau reagent from Ajax Finechem, glacial acetic acid and iron (III) chloride hexahydrate from Merck (Germany).

\subsection{Processing frozen kuini pulp}

M. odorata (kuini) were obtained from MARDI Sintok, Kedah. Kuini fruits were sorted according to the freshness and no physical damage to undergo processing treatment. All selected fruits were rinsed with water using a washer for 15 mins in order to remove all the soil and sand that attached to the surface before being drained. Then, the fruits were placed on a tray in a steam cooker covered with lid and steamed over boiling water at 3 different steaming times $(5,10$, and 15 mins). The fresh fruit without steaming treatment was used as a control for this study. The samples rapidly cooled in ice. After cooled, kuini skin was peeled off and the flesh was grounded using a laboratory grinder to produce kuini pulps (KP). The studied KP was known as KPC (kuini pulps control), KP5 (kuini pulps steaming for 5 mins), KP10 (kuini pulps steaming for 10 mins), and KP15 (kuini pulps steaming for 15 mins). All the KP were then undergoing pasteurization at $90^{\circ} \mathrm{C}$ for two minutes before $100 \mathrm{~g}$ of each studied KP being packed in an aluminium bag and frozen at a temperature $-18^{\circ} \mathrm{C}$ prior analysis. It was stored at the same temperature for 12 months. The initial analysis of the total phenolic content (TPC) and antioxidant activity (FRAP and DPPH methods) of frozen KP was performed within $48 \mathrm{hrs}$ of being packed which considered as 0 months samples. Then, frozen KP was taken out of storage at 2, 4, 6, and 12 months for the same analysis. A schematic diagram of processing kuini fruits was illustrated as in Figure 1.

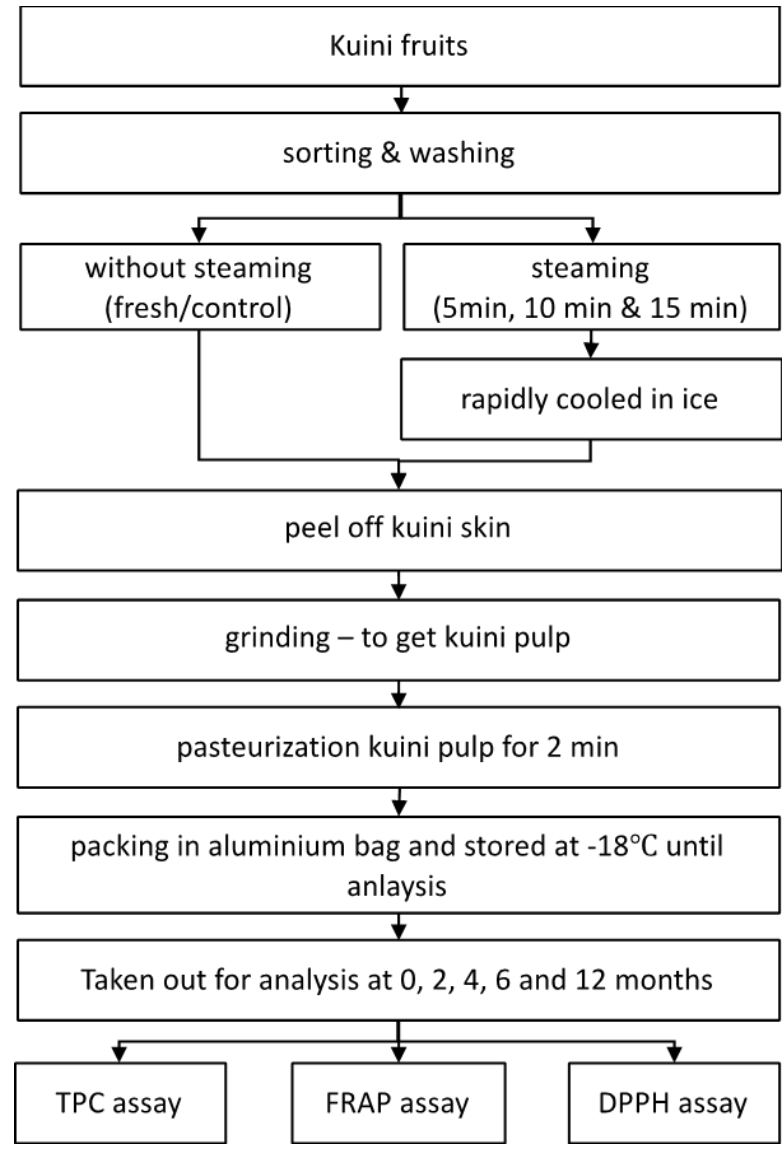

Figure 1. Schematic diagram of processing kuini fruits

\subsection{Determination of dry matter content}

The moisture content of samples was determined in 
triplicate using the method of AOAC (1990). The homogenized sample $(5 \mathrm{~g})$ was placed in a $105^{\circ} \mathrm{C}$ hot air convection oven (Mermet ULM 800, Germany) until the sample reached a constant weight. Then, the dry matter content, which is necessary for calculations were calculated from the obtained moisture value.

\subsection{Extraction of samples}

The kuini pulp underwent extraction with distilled water at a ratio of 1 to $20(\mathrm{w} / \mathrm{v})$. Each mixture was placed in a centrifuge tube and continuous shaking for 1 $\mathrm{hr}$. The mixture was then centrifuged at $8,500 \times \mathrm{g}$ for 10 mins using Sigma 2-16K (Sartorius). The supernatant was filtered through Whatman No. 541 filter paper (Maidstone, UK) to obtain a clear extract. The filtrates were assayed for their total phenolic content (TPC) and antioxidant activity assay (AOA), as described below. All experiments were run in triplicate.

\subsection{Determination of total phenolic content (TPC)}

Total phenolic in all samples was determined with Folin-Ciocalteau assay (Singleton and Rossi, 1965) by using gallic acid as a standard phenolic compound. The fresh weight of each sample was converted into dry weights on the basis of the moisture content. Briefly, $1 \mathrm{~g}$ of samples were dissolved in $20 \mathrm{~mL}$ of distilled water, then $50 \mu \mathrm{L}$ of appropriately extracts solutions and standard gallic acid solutions $(12.5,25.0,50,100$, and $200 \mu \mathrm{g} / \mathrm{mL}$ ) were mixed with $50 \mu \mathrm{L}$ of distilled water in a well of 96-well plate, then $100 \mu \mathrm{L}$ of Folin-Ciocalteau reagent solution (prediluted 10-fold with distilled water) was added. After 6 mins, $100 \mu \mathrm{L}$ of $7.5 \%$ (w/v) $\mathrm{Na}_{2} \mathrm{CO}_{3}$ was added and mixed gently. The reaction mixture was kept in dark for $2 \mathrm{hrs}$ and its absorbance was measured at $765 \mathrm{~nm}$ against distilled water as a blank solution using the microplate reader. The TPC was expressed as $\mathrm{mg}$ gallic acid equivalents (mg GAE/g dry weight) which were determined from known concentrations of gallic acid standard. Data were reported as a mean \pm standard deviation for three replications.

\subsection{Ferric Reducing Antioxidant Power (FRAP) assay}

The ferric reducing antioxidant power (FRAP) assay was performed as previously described by Benzie and Strain (1996). This method was developed to measure the ferric reduction ability of plasma at a low $\mathrm{pH}$. When the ferric 2,4,6-tripyridyl-s-triazine complex $\left(\mathrm{Fe}^{3+}\right.$ TPTZ) is reduced to the ferrous form $\left(\mathrm{Fe}^{2+}-\mathrm{TPTZ}\right)$, an intense blue color is developed. Briefly, The FRAP reagent was prepared by mixing 10 volumes of $300 \mathrm{mM}$ acetate buffer ( $\mathrm{pH} 3.6)$, with one volume of $10 \mathrm{mM}$ TPTZ in $40 \mathrm{mM} \mathrm{HCl}$ and with one volume of $20 \mathrm{mM}$ $\mathrm{FeCl}_{3} \cdot 6 \mathrm{H}_{2} \mathrm{O}$ and the mixture then incubated at $37^{\circ} \mathrm{C}$ for at least 10 mins. A total of $20 \mu \mathrm{L}$ of extract solution and $80 \mu \mathrm{L}$ of distilled water were added to $200 \mu \mathrm{L}$ of freshly prepared FRAP reagent in a well of 96-well plate. After eight min, the absorbance was read using a microplate reader at $593 \mathrm{~nm}$ against reagent blank, which was prepared by the same procedure described above except that extract solution was substituted by $20 \mu \mathrm{L}$ of water. The FRAP value was calculated and expressed as milligram of trolox equivalents per $100 \mathrm{~g}$ of dry weight sample (mg TE /100 g dw) based on a calibration curve plotted using trolox as a standard at a concentration ranging from 12.5 to $200 \mu \mathrm{g} / \mathrm{mL}$.

\subsection{DPPH free radical scavenging assay}

The hydrogen atom or electron donation ability of the corresponding extracts and some pure compounds was measured from the bleaching of purple-colored methanol solution of DPPH. This spectrophotometric assay uses stable radical 2,2-diphenyl-1-picrylhydrazyl (DPPH) as a reagent, according to a slightly modified method of $\mathrm{Lu}$ and Yeap Foo (2000). $100 \mu \mathrm{L}$ of the extracts was added to $200 \mu \mathrm{L}$ of a $0.007 \%$ methanol solution of DPPH. After a 40 mins incubation period at room temperature, the absorbance was read against a blank at $517 \mathrm{~nm}$ using a microplate reader. The percentage of inhibition of free radical DPPH by the extracts was calculated as follow:

$$
\text { Inhibition }(\%)=\left(\mathrm{A}_{\text {blank }}-\mathrm{A}_{\text {sample }} / \mathrm{A}_{\text {blank }}\right) \times 100
$$

Where $\mathrm{A}$ blank is the absorbance of the control reaction (containing all reagents except the test compound), and $\mathrm{A}$ sample is the absorbance of the test compound.

\subsection{Spectrophotometric measurements}

All spectrophotometric measurements were taken using BIOTEK GEN5 Eon Microplate Spectrophotometer (Winooski, Vermont, USA).

\subsection{Statistical analysis}

Each of the measurements described above was conducted in triplicate and the mean data \pm SD (standard deviation) were reported. The data collected were statistically analyzed using the Statistical Analysis Software (SAS) package (version 9.4 of SAS Institute, Inc. Cary, NC, 2008). Statistically significant differences $(p<0.05)$ in the antioxidant properties of the samples were determined by one-way analysis of variance (ANOVA). Duncan Multiple Range Test (DMRT) was used to determine significant differences between the means.

\section{Results and discussion}

\subsection{Effect of steam processing on total polyphenol}


content and antioxidant activity of $M$. odorata (kuini) pulp.

All experimental results of total polyphenolic content (TPC) of KP at 3 different steaming times (KP5, KP10 and KP15) with a comparison of fresh KP without steaming as a control sample (KPC) are summarized in Figure 2. The highest phenolic content was found in KP10 and KP15 at 0 months storage, which had a phenolic content of 265.20 and $262.67 \mathrm{mg} \mathrm{GAE} / 100 \mathrm{~g}$ dry weight respectively $(p<0.05)$. The same pattern was also recorded for both samples at 2, 4, and 12 months of storage. No significant difference was observed between samples $(p>0.05)$. However, at 6 months of storage, KP15 gives the highest total phenolic content compared to others. KPC in all storage months shows the lowest phenolic content compared to KP5, KP10, and KP15. These results show that the steaming process significantly affected $(p<0.05)$ TPC of KP.

To assess the effect in the antioxidant capacity of all KP samples, two established methods for antioxidant activity testing were applied: the FRAP and DPPH assays. These two methods were chosen based on their efficiency, accuracy, and reproducibility. Both methods were already successfully employed in our laboratory for the determination of the antioxidant capacity of a wide range of food, beverages, herbs, and honey samples. The present results showed a good overall correlation between the two assays $(r=0.95)$. All experimental results of antioxidant activity (AOA) of KP at 3 different steaming time (KP5, KP10, and KP15) with a comparison of fresh KP without steaming as a control sample (KPC) are summarized in Figures 3 and 4.
FRAP assay measures the reducing power of a potential antioxidant which reduces the ferric ion $\left(\mathrm{Fe}^{3+}\right)$ to the ferrous ion $\left(\mathrm{Fe}^{2+}\right)$ leading to the formation of a deep blue complex $\left(\mathrm{Fe}^{2+} / \mathrm{TPTZ}\right)$. As shown in Figure 3, the highest FRAP value was observed for KP10 during 0 months of storage which gives the value of $204.55 \mathrm{mg}$ TE/100g dw. KP10 still exhibited the highest FRAP value compared to other samples after 2 and 4 months of storage, which give the FRAP value of 185.52 and $182.85 \mathrm{mg} \mathrm{TE} / 100 \mathrm{~g} \mathrm{dw}$, respectively. However, at 6 and 12 months of storage, the highest FRAP value was recorded for sample KP15 $(p<0.05)$, in which the FRAP value was 145.76 and $104.45 \mathrm{mg} \mathrm{TE} / 100 \mathrm{~g} \mathrm{dw}$ respectively. The increase in the FRAP values followed the same trend seen for the TPC. As we can see, at each of storage months, more than $200 \%$ increases were observed for KP10 and KP15 in comparison with KPC, un-steamed kuini pulp. This result shows that, steaming processing significantly increased FRAP value of kuini pulp $(p<0.05)$.

One of the mechanisms to investigate antioxidant activity is to study the scavenging effect on proton radicals. In the present study, investigation of the total antioxidant capacity was measured as the cumulative capacity of the compounds in the sample that can scavenge free radicals using the DPPH reaction. The presence of antioxidants in the sample leads to the disappearance of DPPH radical chromogens, which can be detected spectrophotometrically at $517 \mathrm{~nm}$ (Abu Bakar et al., 2009). The results of the DPPH assays were summarized in Figure 4. KP10 was found to possess the highest scavenging activity at 0 months storage which

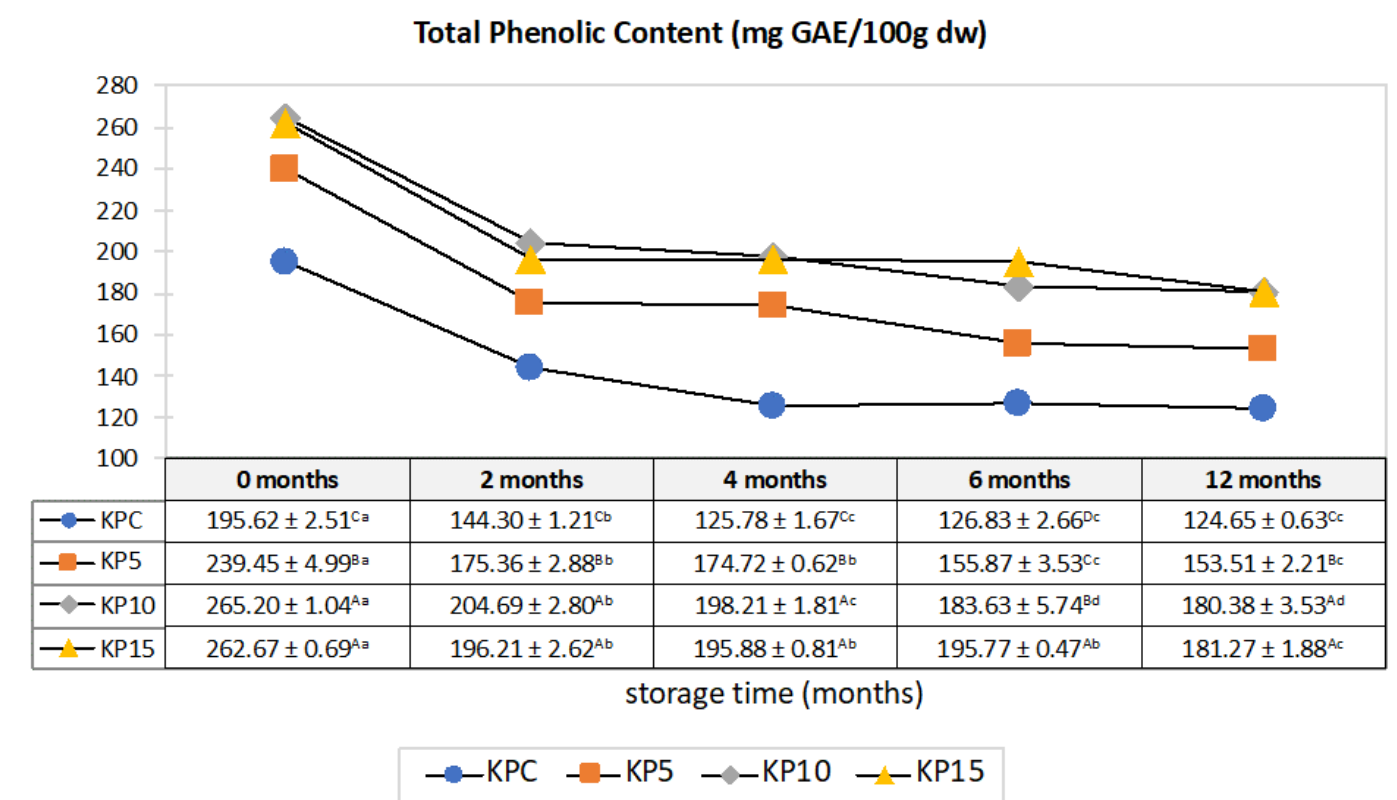

Figure 2. Total polyphenol content (TPC) of KPC, KP5, KP10 and KP15 for 12 months frozen storage at $-18^{\circ} \mathrm{C}$. Values are expressed as mean $\pm \mathrm{SD}, \mathrm{n}=3$. Values with different uppercase superscript within the column are significantly different while values with different lowercase superscript within the row are significantly different $(\mathrm{p}<0.05)$. GAE: gallic acid equivalent; dw: dry weight 
Ferric Reducing Antioxidant Power (FRAP) (mg TE/100g dw)

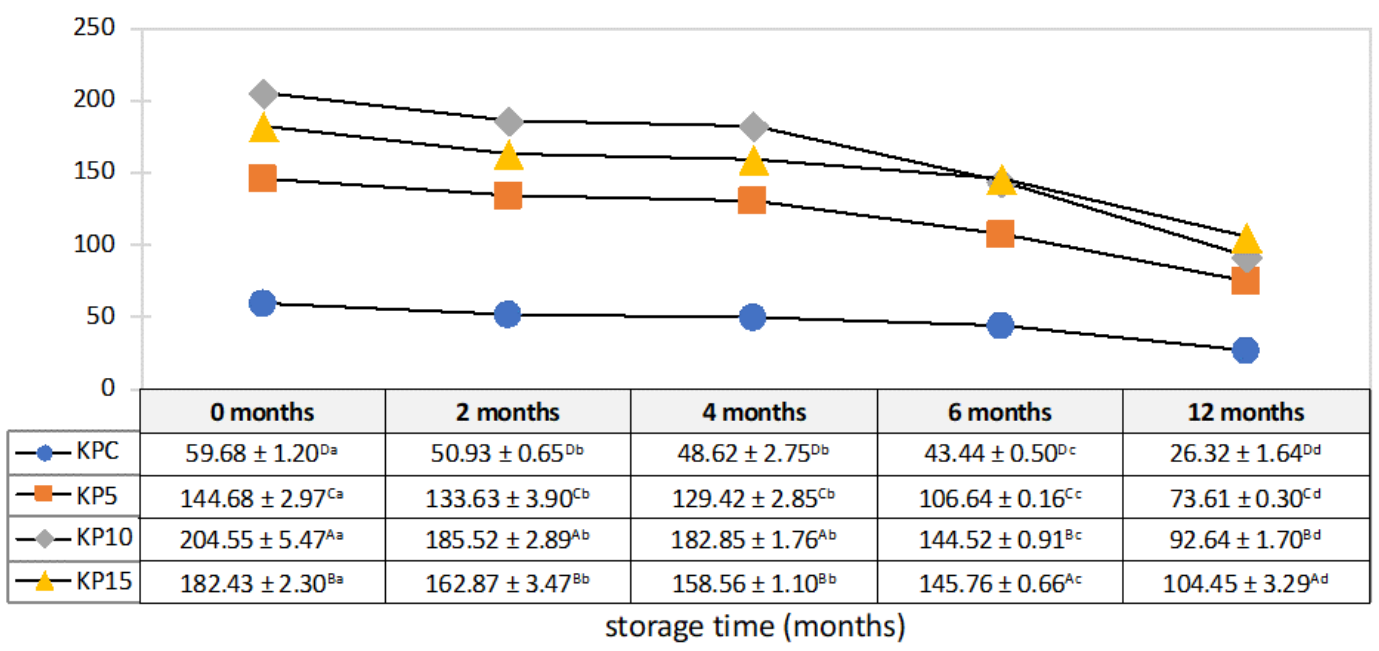

$\leadsto-\mathrm{KPC}-\mathrm{KP5}-\rightarrow-\mathrm{KP} 10--\mathrm{KP} 15$

Figure 3. Reducing power value of KPC, KP5, KP10 and KP15 for 12 months frozen storage at $-18^{\circ} \mathrm{C}$. Values are expressed as mean $\pm \mathrm{SD}, \mathrm{n}=3$. Values with different uppercase superscript within the column are significantly different while values with different lowercase superscript within the row are significantly different $(\mathrm{p}<0.05)$. TE: Trolox equivalent; dw: dry weight

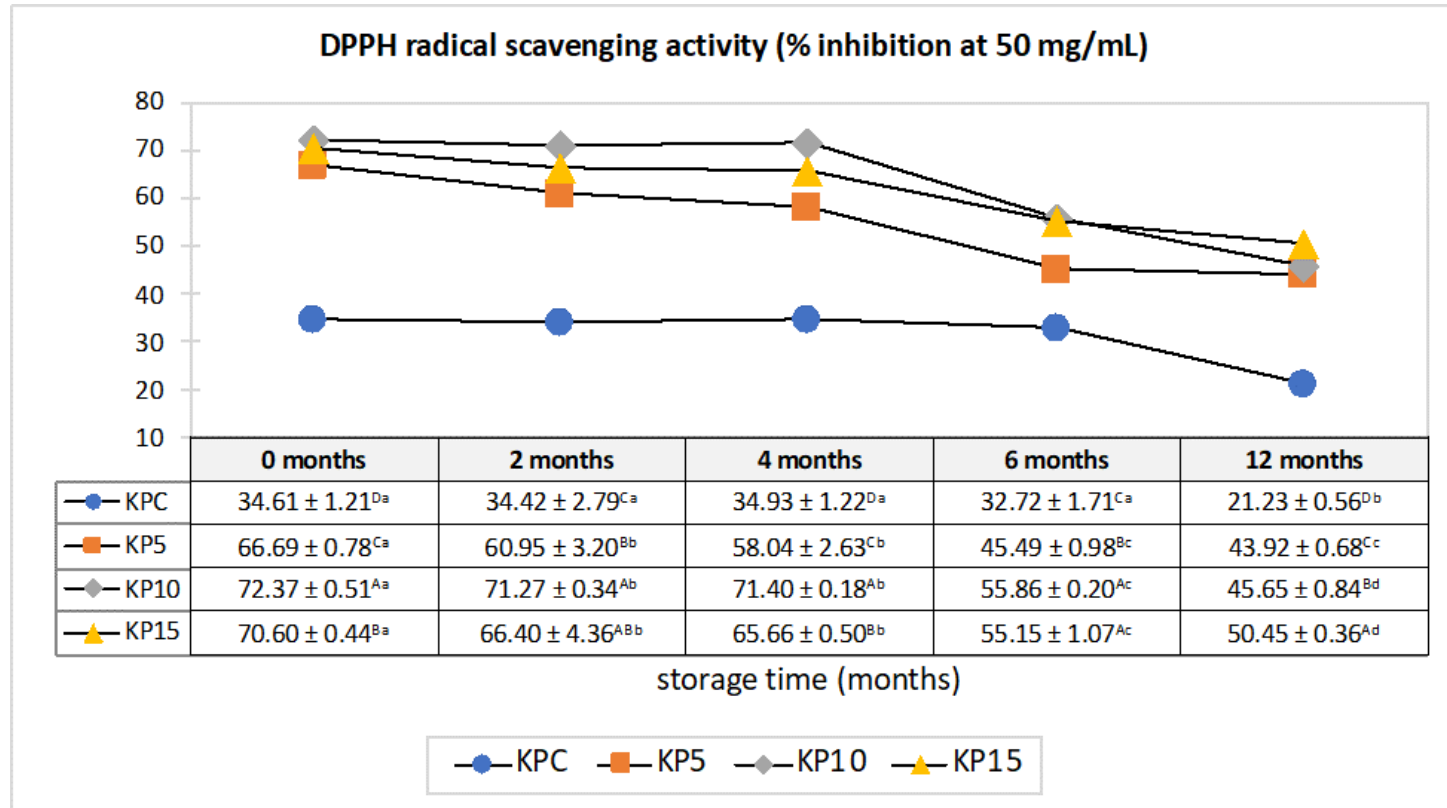

Figure 4. DPPH \% inhibition of KPC, KP5, KP10 and KP15 for 12 months frozen storage at $-18^{\circ} \mathrm{C}$. Values are expressed as mean $\pm \mathrm{SD}, \mathrm{n}=3$. Values with different uppercase superscript within the column are significantly different while values with different lowercase superscript within the row are significantly different $(p<0.05)$.

gives the percentage inhibition of $72.37 \%$. After 2 and 4 months of storage, KP10 still exhibit the highest inhibition percentage, which gives a value of $71.27 \%$ and $71.40 \%$ respectively. There were no significant differences were observed for KP10 compared to other samples at 0,2 , and 4 months of storage $(p>0.05)$. At 6 months of storage, KP10 and KP15 were recorded the highest percentage inhibition of DPPH $(p<0.05)$. However, KP15 shows the highest percentage inhibition of DPPH compared to other samples when storage achieved at 12 months. Same with the obtained result for TPC and FRAP assay, fresh kuini pulp (KPC) was also the lowest radical scavenging activity $(p<0.05)$.
Blanching, whether using steam or hot water is an important food processing step applied to soften the product as well as to inactivate the enzymes that otherwise could cause browning (Nayak et al., 2015). On the other hand, it also increases food safety by microorganism destruction and by antinutritional factors inactivation which suitable for long term storage (Preti et al., 2017). However, most of the food processing including steaming which involved with a thermal process is recognized as one of the major factors on the destruction or changes of natural phytochemicals, which may affect the antioxidant capacity in foods in both positive and negative ways. In our study, steaming processing on kuini fruits for 5, 10, and 15 mins resulted 
in a significant increment $(p<0.05)$ of total polyphenol content and both antioxidant activity in comparison with fresh kuini pulp without steaming process. High temperature has positive effects on the polyphenol contents and antioxidant activity of kuini fruits. Higher polyphenol and antioxidant activities of steaming kuini fruits than fresh ones could be due to the increased release of bound phenolic compounds in the food matrices. Although disruption of cell walls also releases the oxidative and hydrolytic enzymes that can destroy the antioxidants in fruits and vegetables, thermal processing at high temperatures will deactivate these enzymes to avoid the loss of phenolic acids (Dewanto et al., 2002).

Our results are also in agreement with those reported by Amin and Wee (2005) who observed that the total phenolic content of Chinese cabbage increased $(p<0.05)$ after 15 mins of blanching. Talcott et al. (2000) also reported that total water-soluble phenolic compounds were higher in the case of longer blanching time than that of shorter blanching time. Antioxidant properties of steaming kuini fruits for 10 and 15 mins were also higher compared to steaming for 5 mins which could be due to increasing tissue softening and enhanced chemical extraction. Blanching/steaming opens up the cell-matrix and, therefore, could increase the polyphenols yield during extraction that may either enhance or reduce the antioxidant activity (Nayak et al., 2015). Another reason for improved antioxidant activity could be due to the additive and synergistic effects of other phytochemicals such as phenolics and flavonoids (Dewanto et al., 2002). Correspondingly, the antioxidant activity of the bound phytochemical extracts decreased with heating time and temperature as more antioxidative phytochemicals were presumably released (Dewanto et al., 2002). In addition, phenolics usually bound by protein, cellulose or other nutrients in food matrices, also decrease their bioavailability. However, thermal processing could destroy these structures releasing bound phenolics and increasing the phenolic contents (Nayak et al., 2015).

The effectiveness of steam blanching is indicated by the complete inactivation of peroxidase. Therefore, steam blanching time depends on the dimension of the food matrix. For example, blanching time for small size products, such as peas, are 1-2 mins, while for larger products, such as corn on the cob, is 11 mins (Nayak et al., 2015). The longer time required for the temperature rise at the cold spot or slowest heating point, normally the geometric centre, of a relatively large object such as corn on the cob could damage the quality of the kernels, whereas shortening the length of blanching time could reduce the degree of enzyme inactivation and thus result in shorter shelf-life, nutritional and functional value
(Nayak et al., 2015).

Palermo et al. (2014) reported that steaming is the best thermal processing method to preserve phytochemicals in fruits and vegetables. The changes in total phenolics after different types of processing have been reported previously. A comparison study by Zhang et al., (2019) showed that chestnut fruits processed by steaming had the highest phenolics and flavonoids compared to boiling and microwaving. Steaming and other thermal treatments could increase the amount of bound phenolics by chemical reactions, as the oxidations of $o$-diphenols to $o$-quinones give place to polymers and pseudo-melanin material causing the browning of the vegetal tissue (Zhang et al., 2019). The changes in polyphenol content and antioxidant activity could be due the to the use of water during processing in the microwave and boiling, which may have caused the leaching process (Descours et al., 2013) and, consequently, there is less retention of the phenolic compounds in those two methods. It could suggest that the steaming treatment, as did not use water, avoids the solubilization process and therefore obtains greater retention of these compounds (de Lima et al., 2017).

3.2 The changes of total polyphenol content and antioxidant activity of M. odorata (kuini) pulp during 12 months storage at $-18^{\circ} \mathrm{C}$

As visualized in Figure 2, the storage of kuini pulp (KP) had affected TPC. The changes in TPC were observed for all tested KP. After 2 months of storage, TPC value was decreased significantly $(p<0.05)$ for about $25 \%$ decrement for all tested samples. For an example, as exhibit the highest TPC compared to KP5 and KP15, KP10 showed a significant decrease of TPC from $265.20 \mathrm{mg} \mathrm{GAE} / 100 \mathrm{~g} \mathrm{dw}$ (at 2 months) to 183.63 mg GAE/100 g dw after 6 months of storage (about 30\% decrement). A similar trend was also observed for KPC, KP5 and KP15. Overall percentage decrement in the TPC for KPC, KP5, KP10 and KP15 after 12 months of storage in comparison to the initial value at 0 months of storage was ranging from 30 to $36 \%$ decrement TPC value.

As reported earlier, among 4 tested samples, KP10 exhibit the highest FRAP values within each storage months (except for 6 and 12 months, which KP15 gives the highest value). However, along 12 months of storage (Figure 3), a 55\% loss in reducing power was detected at the end of storage (92.64 $\mathrm{mg} \mathrm{TE} / 100 \mathrm{~g} \mathrm{dw})$ in comparison to the initial value (204.55 $\mathrm{mg} \mathrm{TE} / 100 \mathrm{~g} \mathrm{dw}$ ) for KP10. KPC, KP5 and KP15 all exhibited significant decreases in FRAP values at the end of storage (ranging from $40-56 \%$ ). In the present study, all frozen kuini pulps showed significant losses in antioxidant capacity 
measured by the FRAP method at the end of storage ( $p<$ $0.05)$.

The changes in DPPH radical scavenging activity (RSA) assay of tested KP along 12 months of storage was visualized in Figure 4. The losses of the DPPH percentage inhibition after 12 months of storage for KPC, KP5, KP10, and KP15 in comparison to the initial value at 0 months of storage were ranging from $28 \%$ to $38 \%$. However, KPC showed a stable DPPH RSA with no significant difference $(p>0.05)$ were observed at 0 , 2, 4 and 6 months of storage. The decrement of DPPH percentage inhibition begins after 6 months of storage. For samples that undergo the steaming process, the DPPH RSA gives similar decrement pattern for each month of storage.

As we already know, kuini fruits have a very short shelf life. Therefore, their shelf life can be extended by freezing. In this study, after went steam blanching process and grinding to produce pulp, we freeze the pulp at $-18^{\circ} \mathrm{C}$ for 12 months. As far as we concern, this is the first study that has reported the changes of TPC and AOA of kuini pulp during 12 months of frozen storage. Therefore, there is no similar study on kuini fruits to be compared with this finding. However, the comparison was based on treatment and storage study on the other fruits and vegetables to discuss the outcome of this study.

This study had shown that steam blanching treatment had increased the TPC and AOA of the kuini pulp. However, frozen storage of those treated kuini pulps may affect the value of the polyphenol content and antioxidant activity throughout the year. As shown in Figure 2 to 4 , a significant decrease $(p<0.05)$ of polyphenol content and antioxidant activity was observed in all samples. The freezing process had a little effect on the total phenolic content of kuini pulp during 12 months of frozen storage. As we found in this study, polyphenol content was significantly $(p<0.05)$ decreased by more than $30 \%$ after 12 months of frozen storage for each sample (Figure 2). The possible reason behind the decreased in TPC for all kuini pulp samples could be oxidation, hydrolysis, or isomerization of the polyphenolic compound that take place during long-term storage (Šamec and Piljac-žegarac, 2015). This decrease might also relate to the increase of polyphenol oxidase (PPO) enzyme activity of the kuini pulp. A study by De Ancos et al. (2000) demonstrated that PPO enzyme activity of raspberry cultivars was changed during freezer storage. The losses of phenolic compounds in some Saskatoon berry cultivars can be related to increases in PPO enzyme activity during storage in these fruits (De Ancos et al., 2000).
Total phenolics content has special importance in evaluating the antioxidant quality of fruits. The decrease in polyphenol content after 12 months of frozen storage was also influence the antioxidant activity of kuini pulp. Both assays for antioxidant activity show a significant decrease $(p<0.05)$ after stored for 12 months. About $50 \%$ loss was recorded for reducing power value and $30 \%$ loss of DPPH RSA at the end of storage in comparison with 0 months storage. Decrease of antioxidant activity during storage can be attributed to a decreased level of total phenolics, phenolic acids, vitamin $\mathrm{C}$, and other compounds like anthocyanins, carotenoids, and flavonoids when the fruits and vegetables are stored (Galani et al., 2017).

These results showed that frozen storage at $-18^{\circ} \mathrm{C}$ cannot preserve the phenolic components and antioxidant activity of kuini pulp. Same as the result of Poiana et al., (2010) they were reported that freezing at $-18^{\circ} \mathrm{C}$ can decrease bioactive components of strawberry, sweet cherry, and sour cherry juices. The decrease in the bioactive compounds was due to water content in the non -frozen state. The activity and enzymatic reaction rate reached maximum values in the layers of liquid water in frozen fruits. Perhaps, this phenomenon contributes to the modification of chemical compounds, including biologically active substances (Poiana et al., 2010).

\section{Conclusion}

Steam blanching is known to cause the minimum losses in phytochemicals and antioxidant capacity. From this research, steaming methods seemed to preserve better polyphenol content and antioxidant activity of kuini fruits compared to the un-blanched samples, which indicated that bioactive compounds in kuini fruits were very sensitive to heat treatment. Steam blanching for 10 and 15 min seemed to preserve better polyphenol content and antioxidant activity compared to control and $5 \mathrm{~min}$ steaming. Control samples (without steaming treatment) give the lowest amount of TPC and AOA in all samples at each storage month $(0,2,4,6$, and 12 months). The data on total polyphenol were in good agreement with both antioxidant activity $(\mathrm{r}=0.83$ for FRAP and $\mathrm{r}=0.82$ for DPPH). Our findings revealed that steaming for 10 min and 15 mins time led to higher phenolic contents and antioxidant activity. From the obtained result, we choose to steam for 10 mins as the critical point to increase phenolic content and antioxidant activity of frozen kuini pulp. Meanwhile, it can be concluded that the effect of storage in the frozen state significantly affects polyphenol content and antioxidant activity in kuini fruits. TPC and AOA of all samples show a significant decrease $(p<0.05)$ start after 2 months of storage and keep decreasing up to 12 months. Further data collection 
would be needed to determine the best method to preserve the bioactive compound that possesses the antioxidant capacity of kuini pulp during storage.

\section{Conflict of interest}

We declare that there is no conflict of interest regarding the publication of this paper.

\section{Acknowledgement}

The author acknowledges with gratitude the financial support given by Malaysia Agricultural Research and Development Institute (MARDI) under Project PRF407.

\section{References}

Abu Bakar, M.F., Mohamed, M., Rahmat, A. and Fry, J. (2009). Phytochemicals and antioxidant activity of different parts of bambangan (Mangifera pajang) and tarap (Artocarpus odoratissimus). Food Chemistry, 113(2), 479-483. https://doi.org/10.1016/ j.foodchem.2008.07.081

Amin, I. and Wee, Y.L. (2005). Effect of different blanching times on antioxidant properties in selected cruciferous vegetables. Journal of the Science of Food and Agriculture, 85(13), 2314-2320. https:// doi.org/10.1002/jsfa.2261

AOAC. (1990). Official methods of analysis. 15th ed. Arlington, VA: Association of Official Analytical Chemists

Benzie, I.F.F. and Strain, J.J. (1996). The Ferric Reducing Ability of Plasma (FRAP) as a Measure of 'Antioxidant Power ': The FRAP Assay. Analytical Biochemistry, 239(1), 70-76. https:// doi.org/10.1006/abio.1996.0292

De Ancos, B., Gonzalez, E. M. and Cano, M.P. (2000). Ellagic acid, vitamin $\mathrm{C}$, and total phenolic contents and radical scavenging capacity affected by freezing and frozen storage in raspberry fruit. Journal of Agricultural and Food Chemistry, 48(10), 45654570. https://doi.org/10.1021/jf0001684

de Lima, A.C.S., da Rocha Viana, J.D., de Sousa Sabino, L.B., da Silva, L.M.R., da Silva, N.K.V. and de Sousa, P.H.M. (2017). Processing of three different cooking methods of cassava: Effects on in vitro bioaccessibility of phenolic compounds and antioxidant activity. LWT - Food Science and Technology, 76(Part B), 253-258. https:// doi.org/10.1016/j.lwt.2016.07.023

Descours, E., Hambleton, A., Kurek, M., Debeaufort, F., Voilley, A. and Seuvre, A. M. (2013). Aroma behaviour during steam cooking within a potato starch-based model matrix. Carbohydrate Polymers,
95(1), $\quad 560-568$.

https://doi.org/10.1016/ j.carbpol.2013.03.030

Dewanto, V., Wu, X. and Liu, R.H. (2002). Processed sweet corn has higher antioxidant activity. Journal of Agricultural and Food Chemistry, 50(17), 49594964. https://doi.org/10.1021/jf0255937

Galani, J.H.Y., Patel, J.S., Patel, N.J. and Talati, J.G. (2017). Storage of fruits and vegetables in refrigerator increases their phenolic acids but decreases the total phenolics, anthocyanins and vitamin $\mathrm{C}$ with subsequent loss of their antioxidant capacity. Antioxidants, 6(3) 59. https:// doi.org/10.3390/antiox6030059

Khoo, H.E., Ismail, A., Mohd-Esa, N. and Idris, S. (2008). Carotenoid content of underutilized tropical fruits. Plant Foods for Human Nutrition, 63(4), 170175. https://doi.org/10.1007/s11130-008-0090-z

Kim, M.H., Kim, J.M. and Yoon, K.Y. (2013). Effects of blanching on antioxidant activity and total phenolic content according to type of medicinal plants. Food Science and Biotechnology, 22(3), 817-823. https:// doi.org/10.1007/s10068-013-0150-5

Lu, Y. and Yeap Foo, L. (2000). Antioxidant and radical scavenging activities of polyphenols from apple pomace. Food Chemistry, 68(1), 81-85. https:// doi.org/10.1016/S0308-8146(99)00167-3

Mirfat, A.H.S., Idris, S. and Razali, M. (2016). Natural antioxidant properties of selected wild Mangifera species in Malaysia. Journal of Tropical Agriculture and Food Science, 44(1), 63-72.

Nayak, B., Liu, R.H. and Tang, J. (2015). Effect of Processing on Phenolic Antioxidants of Fruits, Vegetables, and Grains-A Review. Critical Reviews in Food Science and Nutrition, 55(7), 887918. https://doi.org/10.1080/10408398.2011.654142

Norlidawati, A.B. and Nik Rozana, N.M.M. (2016). Underutilized Fruits Species Conservation in Malaysia. FFTC Agricultural Policy Platform. Retrieved from http://ap.fftc.agnet.org/ap_db.php? id $=678$

Nur Fatimah, L., Nurul Shazini, Azizah, H., Roselina, K., Pak Dek, Mohd Sabri, P.D. and Radhiah, S. (2019). Effects of different extraction solvents on polyphenols and antioxidant capacity of peel, pulp and seed kernel of kuini (Mangifera odorata). Oriental Pharmacy and Experimental Medicine, 19(3), 277-286. https://doi.org/10.1007/ s13596-019-00383-z

Palermo, M., Pellegrini, N. and Fogliano, V. (2014). The effect of cooking on the phytochemical content of vegetables. Journal of the Science of Food and Agriculture, 94(6), 1057-1070. https:// 
doi.org/10.1002/jsfa.6478

Poiana, M.A., Moigradean, D. and Alexa, E. (2010). Influence of home-scale freezing and storage on antioxidant properties and color quality of different garden fruits. Bulgarian Journal of Agricultural Science, 16(2), 163-171.

Preti, R., Rapa, M. and Vinci, G. (2017). Effect of Steaming and Boiling on the Antioxidant Properties and Biogenic Amines Content in Green Bean (Phaseolus vulgaris) Varieties of Different Colours. Journal of Food Quality, 2017, 5329070. https:// doi.org/10.1002/jsfa.6478

Rossi, M., Giussani, E., Morelli, R., Lo Scalzo, R., Nanic, R. C. and Torreggiani, D. (2003). Effect of fruit blanching on phenolics and radical scavenging activity of highbush blueberry juice. Food Research International, 36(9-10), 999-1005. https:// doi.org/10.1016/j.foodres.2003.07.002

Salma, I., Khadijah, A., Masrom, H., Azuan, A., Raziah, M.L and Abdul Rahman, M. (2010). Distribution and diversity of Mangifera species on farm in Malaysia. Journal of Tropical Agriculture and Food Science, 38(1), 89-95.

Šamec, D. and Piljac-žegarac, J. (2015). Fluctuations in the Levels of Antioxidant Compounds and Antioxidant Capacity of Ten Small Fruits During One Year of Frozen Storage Fluctuations in the Levels of Antioxidant Compounds and Antioxidant Capacity of Ten Small Fruits During One Year of Frozen S. International Journal of Food Properties, 18(1), 21-32. https:// doi.org/10.1080/10942912.2013.790423

Serafini, M. (2006). The role of antioxidants in disease prevention. Medicine, 34(12), 533-535. https:// doi.org/10.1053/j.mpmed.2006.09.007

Singleton, V.L. and Rossi, J.A. (1965). Colorimetry of total phenolics with phosphomolybdic posphotungustic acid reagent. American Journal of Enology and Viticulture, 16, 144-158.

Talcott, S.T., Howard, L.R. and Brenes, C.H. (2000). Contribution of peridern material and blanching time to the quality of pasteurized peach puree. Journal of Agricultural and Food Chemistry, 48(10), 45904596. https://doi.org/10.1021/jf0004309

Zhang, F., Liu, F., Abbasi, A.M., Chang, X. and Guo, X. (2019). Effect of steaming processing on phenolic profiles and cellular antioxidant activities of castanea mollissima. Molecules, 24(4), 1-13. https:// doi.org/10.3390/molecules 24040703 